\title{
Retrospective Analytic Study of Neurosurgical Patients Who Developed Postoperative Hydrocephalus
}

\author{
Ramesh Chandra Venkata Vemula ${ }^{1} \quad$ B. C.M. Prasad ${ }^{1} \quad$ Kunal Kumar $^{1}$ \\ ${ }^{1}$ Department of Neurosurgery, Sri Venkateswara Institute of \\ Address for correspondence Kunal Kumar, MBBS, MS, Department \\ Medical Sciences (SVIMS), Tirupati, Andhra Pradesh, India \\ of Neurosurgery, Sri Venkateswara Institute of Medical Sciences \\ (SVIMS), Tirupati 517501, Andhra Pradesh, India \\ (e-mail: kunwar85ms@gmail.com)
}

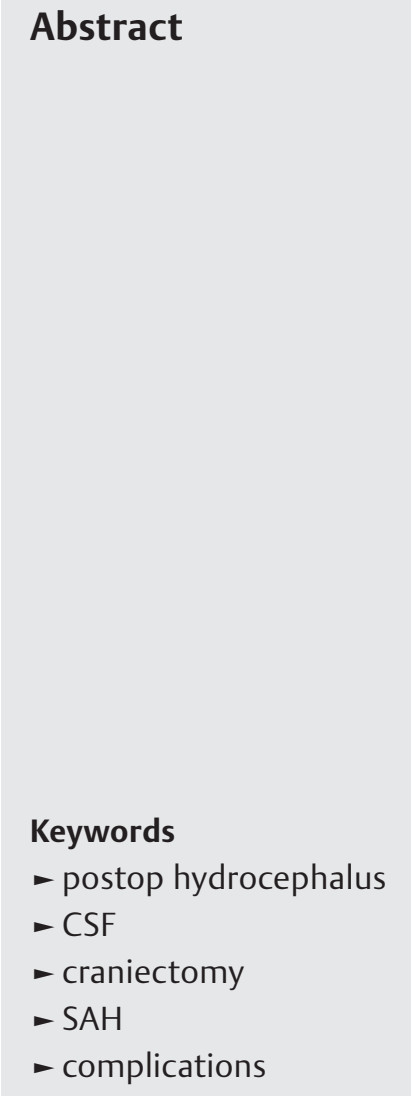

\section{Introduction}

Hydrocephalus is one of the most common pathologies in neurosurgical practice. Not a disease entity in itself, it represents the disturbed equilibrium between the production, flow, and absorption of cerebrospinal fluid (CSF) along the ventricular system. It presents with signs of raised intracranial pressure

published online September 29, 2020
Objective This article discusses the causes, primary pathologies, management, and prognosis of patients who did not have hydrocephalus in preoperative stage, underwent definitive surgical procedure, and developed postoperative hydrocephalus requiring cerebrospinal fluid (CSF) diversion procedures.

Methods Retrospective data collection was done from operation theatre (OT) department database and patient records were obtained for the patients after, related literature was searched, all possible risk factors were analyzed, and our results were compared with other studies.

Results A total of 80 cases were found eligible for the study. Decompressive craniectomy was the most common cause followed by aneurysmal subarachnoid hemorrhage (SAH), intraventricular, and cerebellopontine angle (CPA) tumors. Rate of postsurgical hydrocephalus was 15 to $16 \%$. Cases of decompressive craniectomy presented late, only few cases required diversion procedures during the immediate postop period, mostly aneurysm cases and tumors bed bleed. Out of total 6 mortalities, none of them were directly attributable to hydrocephalus. Since most patient presented after initial stabilization, permanent ventriculoperitoneal shunting was found to be the best option.

Conclusion Cases of decompression surgery should be under vigilant follow-up after discharge and even after cranioplasty for risk of development of hydrocephalus and requirement of permanent shunting. Cases with intraventricular hemorrhage or SAH should be considered as future candidate with risk of developing hydrocephalus. Lamina terminalis opening whenever possible results in favorable outcome in cases of anterior circulation aneurysms. CSF protein analysis in cases of intraventricular and CPA tumors should be done whenever possible, preferably routinely.
(ICP), with or without associated features of primary pathology. It is traditionally classified as obstructive or nonobstructive; communicating or noncommunicating; acute, subacute, and chronic; and primary or secondary.

Hydrocephalus is treated by internal or external diversion of CSF (with management of primary pathology as and when indicated), which may be temporary or permanent diversion.

(C)2020. Neurotrauma Society of India.

This is an open access article published by Thieme under the terms of the Creative Commons Attribution-NonDerivative-NonCommercial-License, permitting copying and reproduction so long as the original work is given appropriate credit. Contents may not be used for commercial purposes, or adapted, remixed, transformed or built upon. (https://creativecommons.org/licenses/by-nc-nd/4.0/). Thieme Medical and Scientific Publishers Pvt. Ltd. A-12, 2nd Floor, Sector 2, Noida-201301 UP, India 
Till date various causes of hydrocephalus have been enumerated in the literature, but we find very few mention of hydrocephalus occurring after surgery.

As we recognized in our operated cases, where hydrocephalus was not present before surgery, but developed hydrocephalus after surgery, that is, postoperative hydrocephalus, either during admission or in the follow-up period, finally requiring CSF diversion procedures, temporary or permanent, it prompted us to search the literature, data, and perform this study.

We could not find any study of this type including all the primary neurosurgical pathologies that required postop CSF diversion procedure, but similar studies including specific neurosurgical pathologies were found to guide our study.

\section{Objectives}

$>$ To discuss the cause, primary pathologies, management, and prognosis of patients who underwent unanticipated CSF diversion procedures postop, operated primarily for neurosurgical pathology not associated with hydrocephalus in the preop stage.

$>$ To identify possible risk factors for development of postop hydrocephalus and anticipation for timely intervention.

\section{Materials and Methods}

The study was conducted in the Department Of Neurosurgery, Sri Venkateswara Institute of Medical Sciences (SVIMS), Tirupati, Andhra Pradesh, India. Patients who underwent their primary surgery from 2010 to 2019, in whom there was no hydrocephalus in preoperative stage, but developed hydrocephalus in postoperative stage, were included in the study.

Retrospective data was collected for all patients who developed postoperative hydrocephalus from OT database and further details from Medical Record Section and Radiology database.

Hydrocephalus was defined either on clinical and/or radiological basis:

1. Evans' ratio $>0.3$.

2. Temporal horn width $>2 \mathrm{~mm}$.

3. Clinical signs of raised ICP.

Those patients who underwent CSF diversion procedure in the postoperative period, their preoperative and postoperative scans were compared. Only those patients in whom hydrocephalus was not found to be present in the preoperative imaging (either computed tomography [CT]/magnetic resonance imaging scan) were included in the study (-Fig. 1).

Related literature with keywords-"post-operative hydrocephalus," "post-surgical hydrocephalus," "hydrocephalus developing after surgery"-was searched on online journal portals; all possible neurosurgical pathologies which featured in the search were noted.

A list of pathologies were made in sequential order as per their respective percentage in our study, then further pathology-specific search was made, for example, "post-operative hydrocephalus after decompressive craniectomy,"

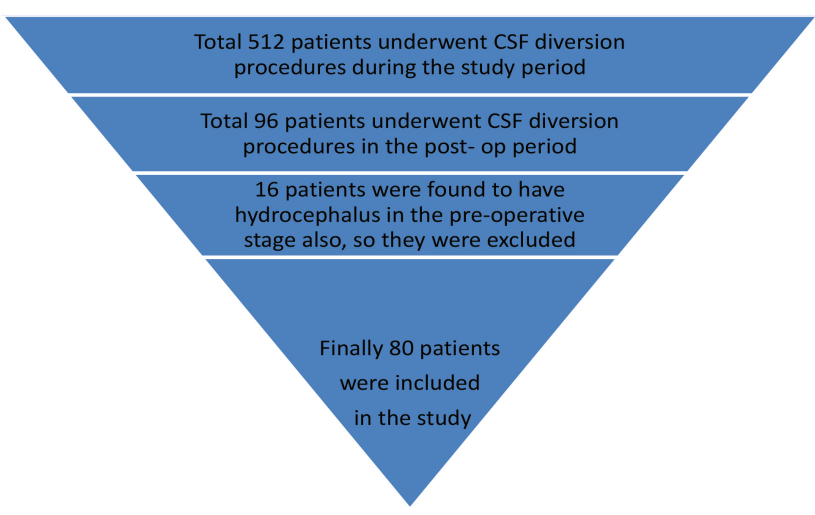

Fig. 1 Methodology for patient selection for the study.

"post-op hydrocephalus after traumatic brain injury," post-operative hydrocephalus after sub-arachnoid hemorrhage," "post-operative hydrocephalus in vestibular schwannoma," etc.

Based on the results of relevant searched journals various risk factors weather related to patient factor, disease factor, and/or surgery were noted for each disease, all possible similar data (if available) was retrieved from our patients, and compared with those of other studies.

Rate of postop hydrocephalus was calculated for each disease category and compared with other similar studies, all possible risk factors were enlisted, and those with significant association in our study were marked in bold letters; other possible risk factors which could not be confirmed from our study were mentioned in normal pattern (without bold mark) (-Table 1).

\section{Management Protocol}

After confirmation of hydrocephalus developing in the postoperative stage, decision for intervention for CSF diversion and the method of CSF diversion to be used was taken by the senior most operating consultant.

External ventricular drain (EVD) was used as a treatment modality only in acute stages, it was kept for a maximum of 5 days under prophylactic antibiotic coverage and intermittent drainage of CSF. If the patient improved during this period, the EVD was clamped, repeat CT was done after 24 hours, and if patient remained asymptomatic and hydrocephalus subsided on CT scan, EVD was removed; if the patient did not improve in 5 days or was suspected to require drainage for more than 5 days, or became symptomatic after clamping EVD, then EVD was converted to ventriculoperitoneal (VP) shunt or endoscopic third ventriculostomy (ETV). In none of the cases, EVD was used out of acute stage (i.e., after 3 days of surgery). Until and unless contraindicated (absolute or relative), right (nondominant side) Kocher's point was used for EVD.

ETV was used in selected cases who developed hydrocephalus in the subacute stage, all of them belonging to postoperative cases of intraventricular tumors (except one case of thalamic tumor postsurgery) to have the benefit of second look also. Similar to EVD, until and unless contraindicated 
Table 1 Risk factors for postoperative hydrocephalus (disease specific)

\begin{tabular}{|c|c|}
\hline Traumatic brain injury & Aneurysmal SAH \\
\hline $\begin{array}{l}\text { Younger age }(<40 \mathrm{y}) \\
\text { Raised ICP } \\
\text { Severe brain injury with poor GCS }(<8) \\
\text { IVH/SAH } \\
\text { SDH >> Contusion > EDH } \\
\text { Postop meningitis/intracranial infection } \\
\text { Craniectomy distance from midline }(<2.5 \mathrm{~cm}) \\
\text { Craniectomy size }\left(>162 \mathrm{~cm}^{2}\right) \\
\text { Postop hygroma } \\
\text { Time to cranioplasty }(>30 \mathrm{~d})\end{array}$ & $\begin{array}{l}\text { IVH } \\
\text { SAH } \\
\text { Poor admission status - Glasgow Coma Scale and HUNT and HESS } \\
\text { scale } \\
\text { Location of ruptured aneurysm } \\
\text { Age } \geq 60 \\
\text { Lamina terminalis opening } \\
\text { Rehemorrhage } \\
\text { Sex } \\
\text { Clipping vs. Coiling } \\
\text { Meningitis }\end{array}$ \\
\hline Stroke & Intraventricular tumors/Colloid cyst \\
\hline $\begin{array}{l}\text { Preop GCS } \\
\text { Territory involved (ICA > MCA > ACA/PCA) } \\
\text { Hemorrhage / infarct / CSVT } \\
\text { Age } \\
\text { Craniectomy distance from midline }(<2.5 \mathrm{~cm}) \\
\text { Craniectomy size }\left(>162 \mathrm{~cm}^{2}\right) \\
\text { Postop hygroma } \\
\text { Time to cranioplasty ( }>30 \mathrm{~d}) \\
\text { Unilateral atrophic changes } \\
\text { Comorbidities (?hypertension) }\end{array}$ & $\begin{array}{l}\text { Tumor histology } \\
\text { Proteinaceous content of tumor } \\
\text { Chemical meningitis } \\
\text { Intraop bleed } \\
\text { Stenosis/Edema at foramen of Monro } \\
\text { Approach (transcortical/transcallosal/endoscopic) } \\
\text { Extent of resection (partial/near-total/total) }\end{array}$ \\
\hline CPA tumors & Posterior fossa tumors \\
\hline $\begin{array}{l}\text { Average tumor size } \\
\text { CSF protein content } \\
\text { Postop tumor bed bleed } \\
\text { Brain retraction } \\
\text { Duration of surgery } \\
\text { Side } \\
\text { Inhomogenous surface with polycystic tumor } \\
\text { Meningitis } \\
\text { Approach } \\
\text { Use of drill }\end{array}$ & $\begin{array}{l}\text { Age (children > adults) } \\
\text { Tumor bed bleed } \\
\text { Brain retraction } \\
\text { Location (median > paramedian > lateral) } \\
\text { Tumor size } \\
\text { Histology } \\
\text { Extent of resection } \\
\text { Meningitis }\end{array}$ \\
\hline Pituitary and parasellar tumors & Miscellaneous/Others \\
\hline $\begin{array}{l}\text { Tumor bed bleed } \\
\text { Location and extension } \\
\text { Tumor size } \\
\text { Extent of resection } \\
\text { Arachnoid breach } \\
\text { Age } \\
\text { Functioning vs. nonfunctioning } \\
\text { Intraop and postop CSF leak } \\
\text { Endoscopic vs. open } \\
\text { Meningitis }\end{array}$ & $\begin{array}{l}\text { Nature of tumor (dermoid/epidermoid) } \\
\text { Tumors with high protein content } \\
\text { Location near CSF pathways } \\
\text { Subarachnoid seepage of blood } \\
\text { Periventricular postoperative gliosis } \\
\text { Craniotomies crossing midline with possible damage to venous } \\
\text { sinuses } \\
\text { Meningitis } \\
\text { Intraventricular bleed } \\
\text { Tumor bed bleed } \\
\text { Postradiation therapy } \\
\text { Recurrence of tumor } \\
\text { Postsurgical major infarcts }\end{array}$ \\
\hline
\end{tabular}

Abbreviations: ACA, anterior cerebral artery; EDH, extradural hematoma; CPA, cerebellopontine angle; CSF, cerebrospinal fluid; CSVT, cerebral sinovenous thrombosis; GCS, Glasgow Coma Scale; ICA, internal carotid artery; ICP, intracranial pressure; IVH, intraventricular hemorrhage; MCA, middle cerebral artery; PCA, posterior cerebral artery; SAH, subarachnoid hemorrhage.

(absolute or relative), right (nondominant side) Kocher's point was used for ETV, with single burr hole.

In the remaining cases, VP shunt was used for CSF diversion, side and site decided based on individual scans, preferably from the nondominant right side, or side of maximum ventricular dilatation in asymmetrical or unilateral hydrocephalus, or opposite to the side of surgery for primary pathology. Ventricular entry point used was primarily Frasier's point, Kocher's point was used only if the patient already underwent EVD/ETV via that point for revision shunting or if specifically indicated for the patient.
In three patients after decompressive craniectomy for traumatic brain injury and one patient after decompressive craniectomy for stroke, VP shunt was done together with cranioplasty. One patient of decompressive craniectomy for traumatic brain injury underwent VP shunt after cranioplasty.

All cases were operated under general anesthesia, postsurgery CT scan was done at 6 hours after surgery (or more if the patient could not be extubated, but not more than 24 hours).

All surviving patients were discharged in hemodynamically and neurologically stable condition. 
All the patients were followed up at least one visit after discharge within 3 months.

Data was collected, arranged, and segregated in Excel.

\section{Results}

Out of total 512 patients who underwent CSF diversion procedure, either temporary or permanent, 96 patients underwent CSF diversion procedures, out of which 16 patients were found to have hydrocephalus in the preoperative scans also and hence were excluded, remaining 80 patients were included in the study ( - Fig. 1), accounting for $15.63 \%$ of total CSF diversion procedures (-Fig. 2). In other cases, hydrocephalus was present at presentation, and underwent EVD, ETV, or VP shunt surgery f/b definitive surgery (if indicated).

Out of 80 cases who developed postop hydrocephalus, most cases $(18 ; 22.50 \%)$ were those who underwent decompressive craniectomy for traumatic brain injury, either for subdural hematoma (SDH), contusion, or raised ICP refractory to medical management, $\mathrm{f} / \mathrm{b}$ spontaneous subarachnoid cases due to ruptured aneurysms $(13 ; 16.25 \%)$, f/b decompressive craniectomy for stroke $(10 ; 12.50 \%)$, either hemorrhagic or infarct, $\mathrm{f} / \mathrm{b}$ intraventricular tumors including colloid cysts $(9 ; 11.25 \%)$, cerebellopontine (CP) angle (CPA) tumors (8; $10 \%)$, and posterior fossa tumors $(6 ; 7.5 \%)$. Thalamic tumors, pineal region tumors, pituitary tumors, and parasellar tumors had 3 (3.75\%) cases each. Miscellaneous group ( $4 ; 5 \%$ ) consisted of temporal base meningioma, petroclival meningioma, interhemispheric epidermoid, and periventricular arteriovenous malformation ( $\mathbf{- F i g s .} \mathbf{3}$ and $\mathbf{4}$ ).

In our study, male $(\mathrm{M})$ were twice as common as female (F) $(\mathrm{M}=52, \mathrm{~F}=28)$, but in proportion to the number of primary cases, male predominance could be attributed to traumatic brain injury constituting the maximum number.

Most of the cases (38) developed hydrocephalus after 21 days of surgery (chronic), f/b 27 cases between 3 days to 3 weeks (subacute), and f/b 15 cases within 3 days of surgery (acute) (-Fig. 5). This accounted for overall average duration of developing hydrocephalus of 57.81 days, which was more for decompressive craniectomy cases either for traumatic brain injury or stroke (68.58 days) and lesser for aneurysm clipping cases (12.62 days), and 53.19 days for other diseases combined together.

\section{Total CSF diversion procedures $(n=512)$}
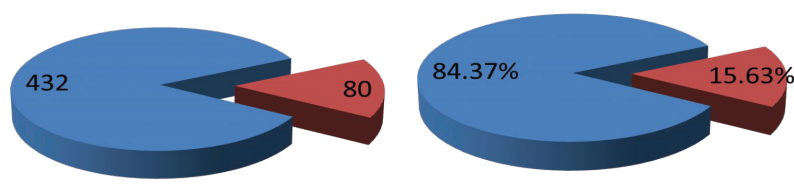

athers post-op hydrocephalus

Fig. 2 Total cerebrospinal fluid (CSF) diversion procedures and number and percentage of postop hydrocephalus.

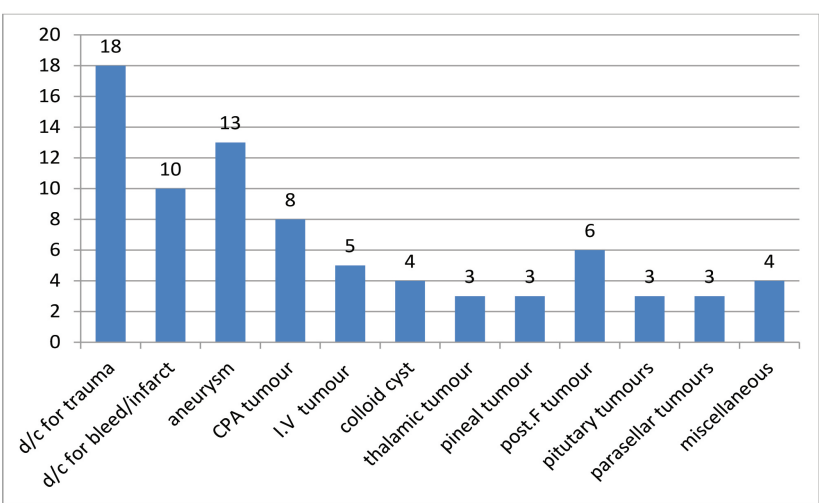

Fig. 3 Various neurosurgical pathology which resulted in postop hydrocephalus.

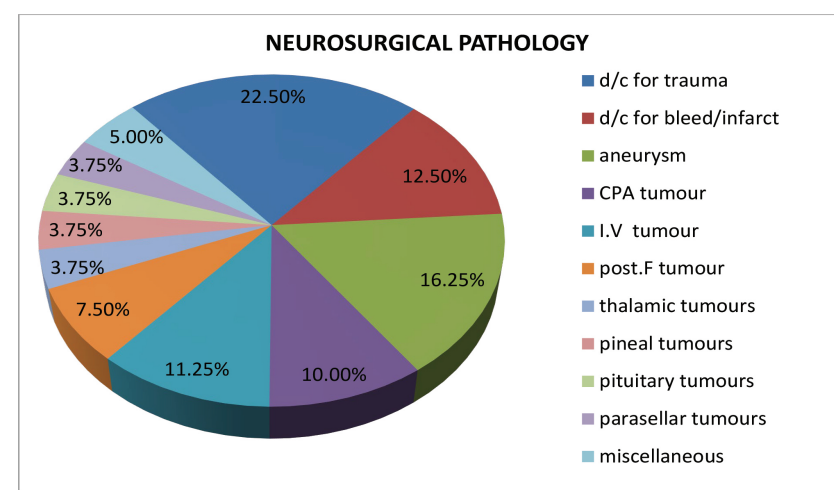

Fig. 4 Percentage wise representation of various neurosurgical pathology which resulted in postop hydrocephalus.

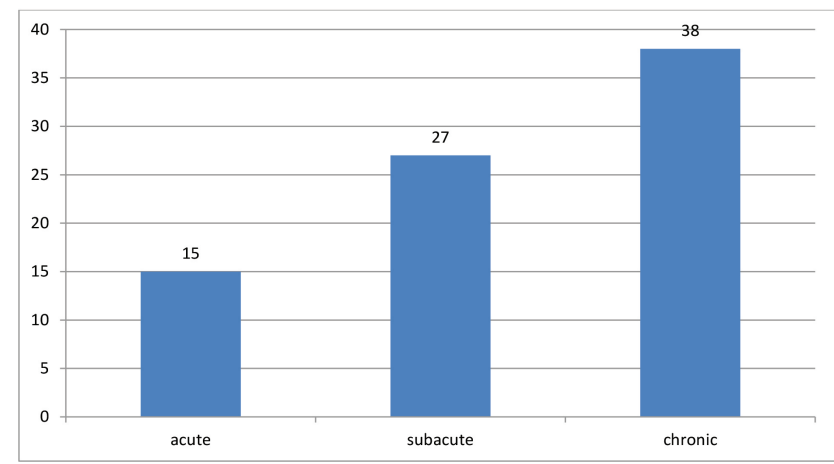

Fig. 5 Acuteness of postop hydrocephalus.

The most common modality selected for CSF diversion was VP shunt (64), f/b EVD in 11 cases and ETV in 5 cases.

\section{Outcome}

Eight (10\%) out of 80 patients who underwent CSF diversion procedures via any of these three modalities required rediversion of CSF, 3 EVD converted to VP shunt, 3 primary shunt failure required reshunting, one ETV required VP shunt, and in one case EVD was converted to ETV (-Fig. 6).

Six patients (7.5\%) died in due course of treatment after CSF diversion procedure, 2 patients had meningitis and were started on broad spectrum antibiotics, 1 patient had 


\section{Re-diversion procedure}
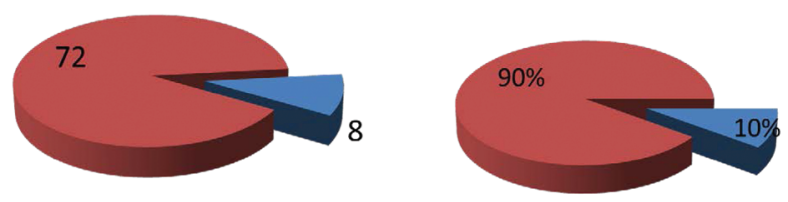

\section{No Yes}

Fig. 6 Number and percentage of cerebrospinal fluid (CSF) rediversion procedure.

persistent vegetative state after tumor bed bleed and did not improved even after VP shunt, in the remaining 3 patients it was not directly related to hydrocephalus and was due to primary pathology with high surgical risk.

Remaining 74 patient's record suggested that all of them followed up for at least one visit within 3 months of discharge after CSF diversion procedure. Sixty-seven patients were independent for self-care and usual activities, 2 patients required some assistance for work, 3 patients required assistance for self-care, and 2 patients were unable to walk and required regular nursing care.

\section{Discussion}

Based on the results, we found that some of the risk factors were common and should be prevented as much as possible as per standard treatment protocols to reduce the risk of postoperative hydrocephalus, for example, meningitis, prolonged and excessive brain retraction, extent of resection, postoperative surgical site bleed, etc.; some risk factor(s) were disease and approach specific.

Postoperative hydrocephalus after decompressive craniectomy was mostly subacute or chronic due to the gradual alteration of CSF autoregulation mechanisms, whereas those occurring after aneurysmal subarachnoid hemorrhage (SAH) surgery were mostly acute because the primary insult (SAH/ intraventricular hemorrhage [IVH]) has already occurred and the chain of events has started by the time patient underwent definitive occlusion of surgery.

\section{Traumatic Brain Injury ${ }^{1-8}$}

Rate of postop hydrocephalus in cases of traumatic brain injury who underwent decompressive craniectomy in our study was $6 \%$, which was comparable to most other studies (6-14\%) (-Fig. 7).

Average age of patients who underwent surgery for postop hydrocephalus in our study was 39.77 years which was also comparable to other studies (31-37.77 years), but less than control population who did not developed hydrocephalus,

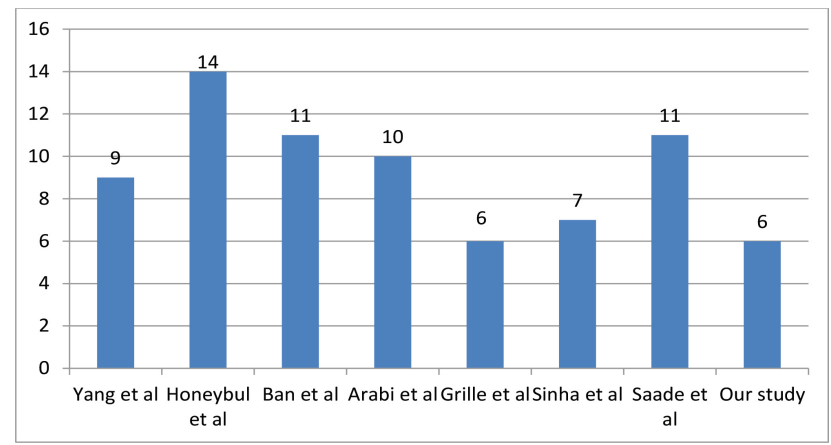

Fig. 7 Rate of postop hydrocephalus in decompressive craniectomy for traumatic brain injury.

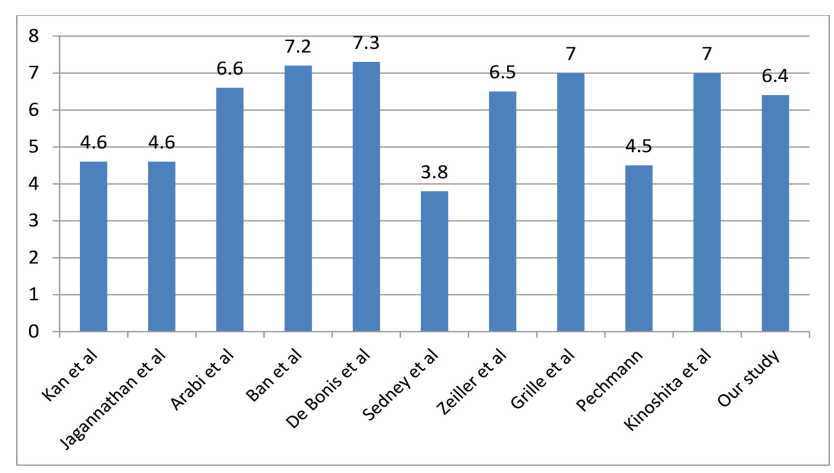

Fig. 8 Average Glasgow Coma Scale (GCS) at presentation of patients who developed postop hydrocephalus after decompressive craniectomy for traumatic brain injury.

showing that younger age was a risk factor for the development of postoperative hydrocephalus, may be due to more number of young patients surviving the acute insult to develop delayed hydrocephalus later on.

Average Glasgow Coma Scale (GCS) at presentation was 6.4 in our study, which was comparable to other studies, common being $<8$ in all studies (-Fig. 8).

Note that $88.8 \%$ cases were found to have SAH in the preop scans, in other studies it ranged from 52.8 to 96\% (- Fig. 9).

Of the 18 traumatic brain injury cases, 12 cases were having SDH, 3 cases were having contusion, 2 cases having both, and 1 case having extradural hematoma associated with SDH, pointing that SDH was a risk factor among primary traumatic insult.

Severity of injury which related to poor GCS and raised average ICP before surgery than the control ones, clearly demonstrated a positive association for development of postoperative hydrocephalus.

Among our 18 patients, SAH was present in 10 patients, IVH in 1 patient, and 2 patients had both SAH and IVH.

We perform craniectomy with average distance of 1 inch from midline as an institute protocol, and we could not find any mention of exact distance from midline in individual cases as in some studies taking $2.5 \mathrm{~cm}$ as cutoff for development of postop hydrocephalus, with inconclusive and conflicting reports. The extent of arachnoid granulation tissue and tributaries of midline venous sinuses varies 


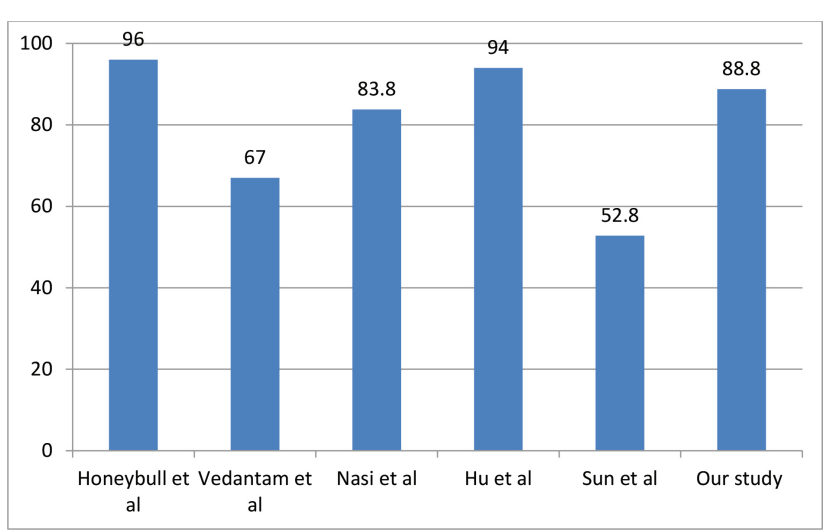

Fig. 9 Percentage of traumatic brain injury patients having subarachnoid hemorrhage (SAH) who developed postop hydrocephalus after decompressive craniectomy for traumatic brain injury.

from individual to individual, hence defining a landmark distance from midline for decompressive craniectomy may not stand universal for all patients, although a distance of $2.5 \mathrm{~cm}$ is been used, and preferably a craniectomy with medial margin less than $2.5 \mathrm{~cm}$ should be avoided in all cases. Craniectomy size varied from individual to individual tailored according to the exact site of pathology (frontal/ temporal/parietal), and it was not found to be a risk factor in our study, but the extent of craniectomy must ensure that the brain is well relaxed and should not just pop-out of the craniectomy defect, wherever required, adequately placed radial dural cuts may be placed. Although some studies mentioned early cranioplasty to be less associated with postoperative hydrocephalus, it was not so in our study. Postop hygroma was associated in some cases with hydrocephalus, but we found it to be separate entity with overlapping risk factors and were not itself a risk factor for postop hydrocephalus.

Pathophysiology: (1) Acute severe traumatic brain injury results in disturbed autoregulation of vascular dynamics due to direct injury to blood vessels, associated SAH may cause localized vasospasm, and raised ICP causes direct compression over the vessels. (2) CSF dynamics and autoregulation in the acute phase is disturbed by compression of cisterns, intraventricular bleeds, SAH, and disruption of arachnoid granulations. (3) Decompressive craniectomy causes reduction of acutely raised ICP which may prevent life-threatening brain herniations, but at the cost of disturbing the pressure volume dynamics of CSF autoregulation. This may be the most suitable reason to explain the development of postoperative hygroma and hydrocephalus ex vacuo on the side of decompressive craniectomy. (4) Injury to arachnoid granulation tissue on the medial aspect of craniectomy and insufficient (small) craniectomy which in fact causes a part of injured and edematous brain to pop out rather than relax adds more to the already disturbed autoregulation of CSF. (5) Moreover, greater risk of infection and meningitis (clinical/subclinical) has been always there in view of emergency surgery, presence of blood clots, and subnormal nutrition and a catabolic state.

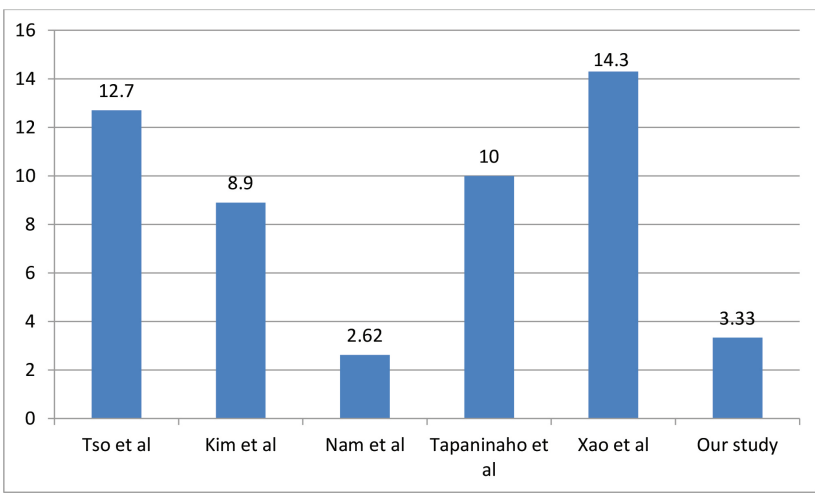

Fig. 10 Rate of postop hydrocephalus in aneurysmal subarachnoid hemorrhage $(\mathrm{SAH})$.

\section{Aneurysmal SAH ${ }^{9-18}$}

Rate of postoperative hydrocephalus in aneurysmal SAH patients was $3.33 \%$ in our study, which was less than that reported in other studies except one, which we attribute to routine opening of lamina terminalis in all of the anterior circulation aneurysm cases in our study ( - Fig. 10). Opening of lamina terminalis provides an easy escape for CSF and opportunity to the brain to develop compensatory mechanism for CSF autoregulation.

Patients who developed postop hydrocephalus were having slightly higher average age (62.2 vs. 58.7 years), higher Fischer grade (Grade II and IV) (-Fig. 11), and poor HUNT and HESS score (Grade IV, III, and V) (-Fig. 12). A higher age as risk factor indicates the aging autoregulation mechanisms with increasing age, whereas poor HUNT and HESS score and higher Fischer grade indicates the severity of the acute insult to the brain and global hypofunction.

Posterior circulation aneurysm were having higher percentage of postop hydrocephalus than anterior circulation, this may be due to delayed presentation, greater operative time, more association with IVH, relatively higher incidence of low-grade meningitis, CSF leak, and pseudomeningocele, causing disturbed CSF regulation (-Fig. 13).

We cannot comment on clipping versus coiling in our study as we do not have endovascular neurosurgery set-up at our institute.

Pathophysiology: (1) SAH-induced vasospasm not only cause local but global disturbance in vascular autoregulation and cerebral metabolism which indirectly leads to disturbances in CSF autoregulation, and hence it correlates with poor HUNT and HESS score at presentation and higher Fischer grades. (2) Intraventricular bleed predisposes for hydrocephalus by obvious means, mechanical obstruction in acute stages and decreased absorption from arachnoid surface in later stages. (3) Posterior circulation aneurysms due to their propensity for delayed presentation with more neck pain and less severe headache bleed directly into infratentorial cisterns and need for larger or complex craniotomies/craniectomies with prolonged surgery and retraction predispose for development of postoperative hydrocephalus. 


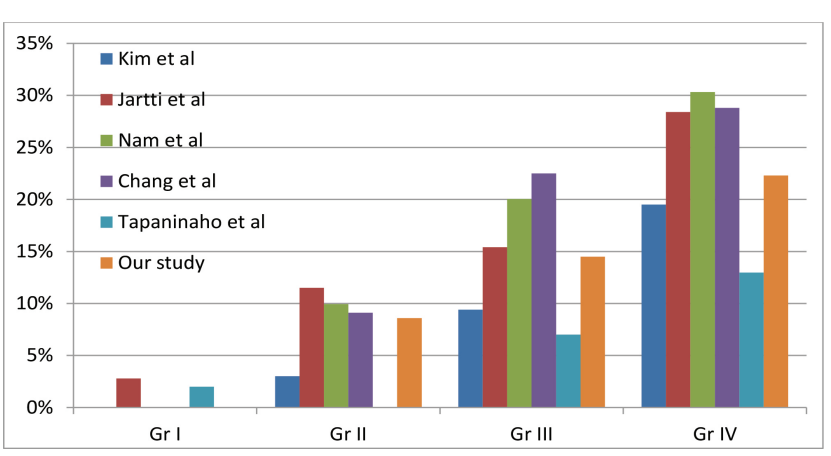

Fig. 11 Comparison of Fischer grade in different studies that developed postop hydrocephalus after surgery for aneurysmal subarachnoid hemorrhage (SAH).

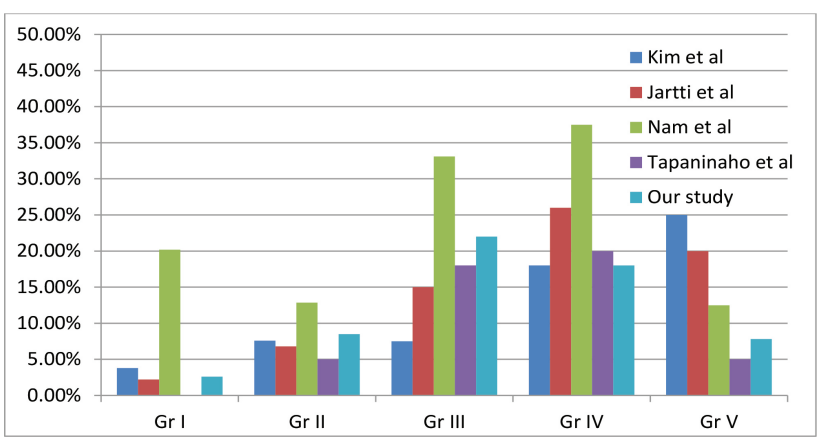

Fig. 12 Comparison of HUNT and HESS grade in different studies of patients who developed postop hydrocephalus after surgery for aneurysmal subarachnoid hemorrhage (SAH).

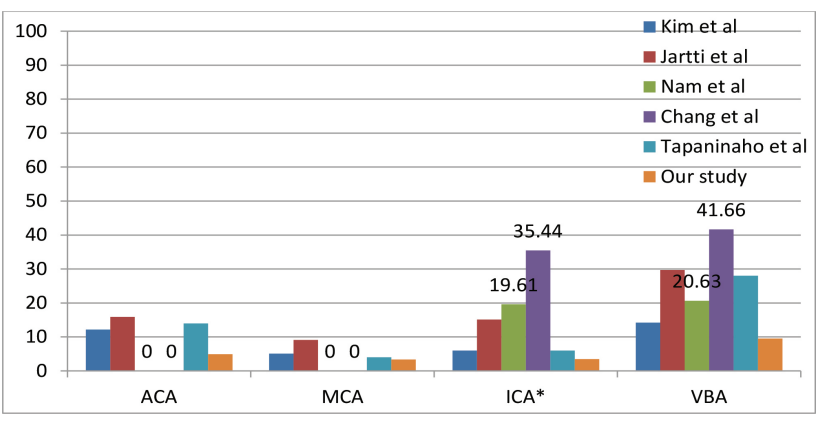

Fig. 13 Comparison of anterior versus posterior circulation aneurysms involved in different studies that developed postop hydrocephalus after surgery for aneurysmal subarachnoid hemorrhage (SAH) ( ${ }^{*}$ Nam et al and Chang et al, ICA aneurysm is representative of all anterior circulation aneurysm in their study).

\section{Stroke ${ }^{19-23}$}

The rate of postoperative hydrocephalus in decompressive craniectomy for stroke patients was $5.71 \%$ in our study, which was far less than all other studies (14.6-44\%) (-Fig. 14).

Poor GCS before surgery and greater infarct area (or volume) were associated with higher risk of development of postoperative hydrocephalus; internal carotid artery territory infarct was most common, f/b middle cerebral artery

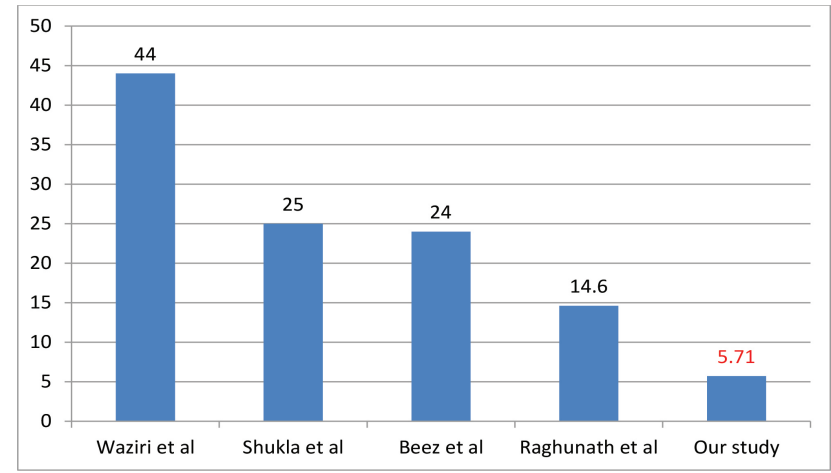

Fig. 14 Rate of postop hydrocephalus after decompressive craniectomy for stroke.

territory and anterior cerebral artery territory infarct, posterior cerebral artery territory infarct was the least commonly associated, probably because posterior suboccipital craniectomy was least supposed to disturb the CSF autoregulation. Infarct was more commonly associated than hemorrhagic stroke (clot evacuation leads to better reduction of raised ICP and return to near normal physiology) and cerebral sinovenous thrombosis (due to lower prevalence and less acute presentation).

Pathophysiology: Similar to traumatic brain injury, stroke causes an acute rise in ICP, leading to a deranged autoregulatory mechanism of CSF and blood. The brain on the pathological side shrinks in due course of time, leading to traction on the opposite hemisphere. Risk factors related to decompressive craniectomy in postoperative stage remains the same as that of those for traumatic brain injury.

\section{Intraventricular Tumors/Colloid Cyst ${ }^{24-30}$}

The rate of postoperative hydrocephalus in intraventricular tumor (including colloid cyst) excision patients was $10.41 \%$ in our study, which was similar to two other studies (Radoi et al and Lee et al), but Alam et al reported a rate of $28.57 \%$ (-Fig. 15). While choosing an endoscopic transforaminal approach, the adequacy of the foramen of Monro to the size of endoscope should be matched and the trajectory should be chosen to avoid excessive mechanical pressure injury at the foramen of Monro. To avoid spillage of tumor contents, any cystic content should be aspirated adequately, and to prevent blood spillage copious saline irrigation or dry field method should be adapted to achieve meticulous hemostasis.

Pathophysiology: Edema at the foramen of Monro or resultant scarring after transforaminal approach may result in acute mechanical obstruction, chemical meningitis, which most probably is supposed to result from tumor degradation products or proteinaceous contents of tumor released during excision of tumor, mechanical blockage of CSF pathway from tumor tissue and blood clot, amount of residual tumor after surgery, postoperative changes, and gliosis leading to unilateral traction over ventricle from side of surgical approach. Open and endoscopic approaches have their own merits and demerits in causation for postoperative hydrocephalus, and weather one is better than other cannot be concluded. 


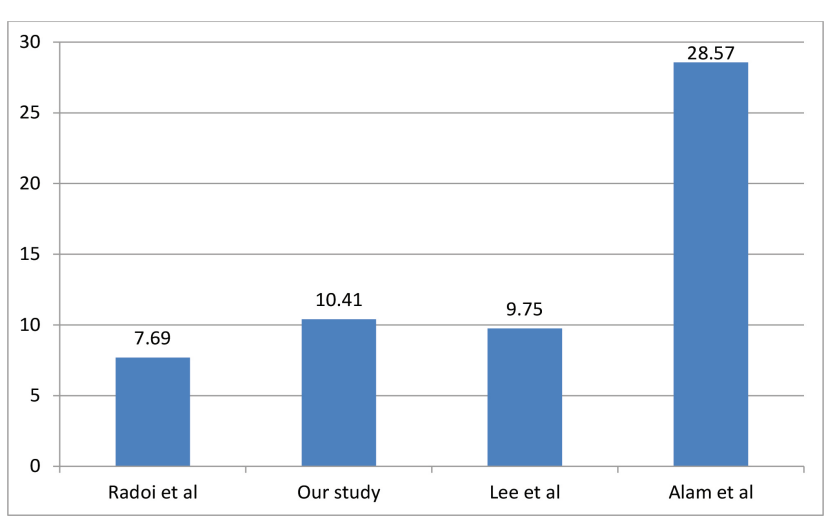

Fig. 15 Rate of postop hydrocephalus after surgery for intraventricular tumors.

\section{CPA Tumors ${ }^{31-36}$}

The rate of postoperative hydrocephalus after surgery for the CP tumors was $5.38 \%$ in our study, which was comparable to other studies. In studies using Gamma knife surgery for vestibular schwannoma, rate of post-operative hydrocephalus ranged from $4-24 \%$ ( - Fig. 16). It is uncommon for larger tumors to present without associated hydrocephalus (especially in Indian population), but among those who do present without associated hydrocephalus, larger and firm tumors signify longer duration of surgery, greater difficulty in excision, prolonged retraction, and higher chances of leaving residual tumor and surgical site hematoma, all of which increases the risk of postoperative hydrocephalus. Choice of approach and use of highspeed drill has been suspected but not proven as cause of risk factors for postoperative hydrocephalus. Epidermoid tumors at CPA (and at other locations also) are supposed to cause chemical meningitis and result in postoperative hydrocephalus.

Pathophysiology: Nonobstructive hydrocephalus has been proven beyond doubt and is attributed to high protein content in the CSF, supposed to be released from the tumor itself which hampers CSF absorption. Higher average CSF protein levels have been found in vestibular schwannomas as compared with normal controls. Obstructive cause is most commonly due to surgical site hematoma, residual tumor, and prolonged retraction.

\section{Posterior Fossa Tumors ${ }^{37-41}$}

The rate of postoperative hydrocephalus in posterior fossa tumors was $3.47 \%$ in our study, which was far less as compared with other studies ( - Fig. 17), which may be because we face most patients with posterior fossa tumors with hydrocephalus at presentation and prefer to do a VP shunt for prior stabilization and plan definitive surgery at a later date. Children are more prone than adults for development for postoperative hydrocephalus due to a greater incidence of posterior fossa tumors in children, greater incidence

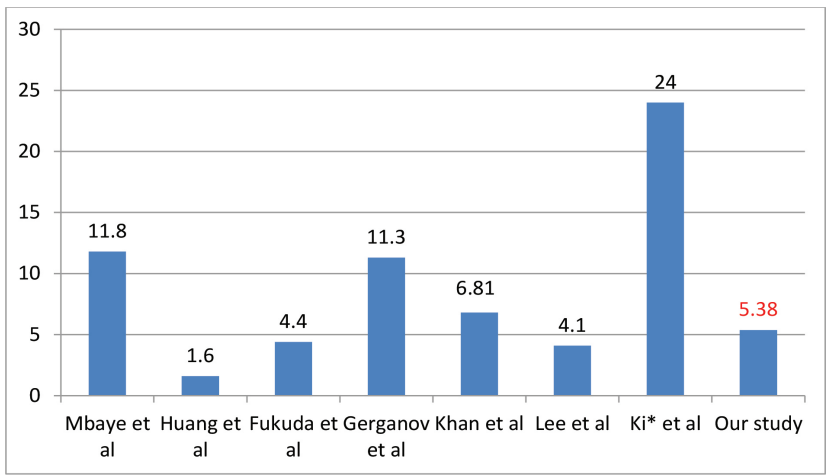

Fig. 16 Rate of postop hydrocephalus after surgery for cerebellopontine angle (CPA) tumors (vestibular schwannoma).

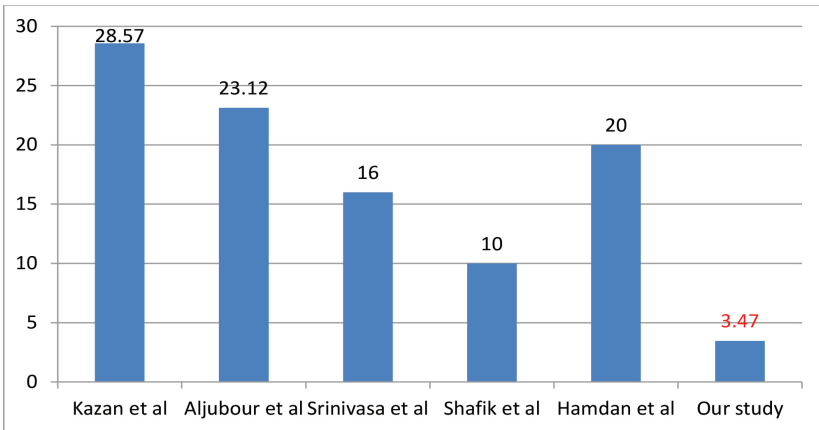

Fig. 17 Rate of postop hydrocephalus after surgery for posterior fossa tumors.

of midline located tumors (than paramedian and lateral location) which in itself are a risk factor, and less well developed compensatory mechanisms. Need for radiation therapy after surgery may also predispose. Other factors like larger size of tumor, prolonged surgery duration, prolonged retraction, and surgical site bleed are obvious risk factors.

Pathophysiology: Direct mechanical compression at the level of fourth ventricle, either by residual tumor or surgical site hematoma, edematous brain tissue, and spillage of blood into the ventricles may all lead to postoperative hydrocephalus.

\section{Pituitary and Parasellar Tumors ${ }^{42-46}$}

$>$ The rate of postoperative hydrocephalus after surgery for sellar and parasellar tumors (including pituitary tumors) was $3.07 \%$ in our study, which was comparable to other studies (0.8-8\%) (-Fig. 18). Tumor size, extent of tumor with extension into the floor of third ventricles and beyond, amount of residual tumor, surgical site hematoma, and breach of arachnoid with spilling of blood in the 
subarachnoid space were noted as probable risk factors in different studies.

Pathophysiology: Postoperative hydrocephalus developing after surgery for sellar and parasellar tumors is more of obstructive type, with compression at the level of the third

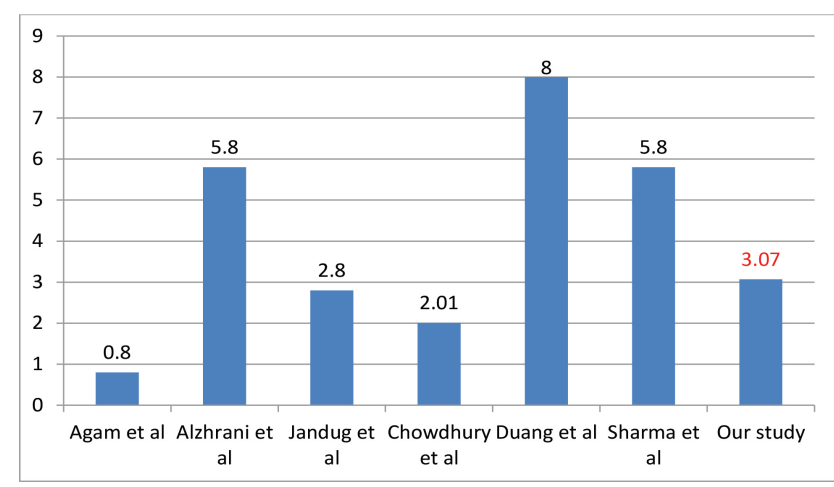

Fig. 18 Rate of postop hydrocephalus after surgery for sellar/ parasellar tumors. ventricle floor. Blood seeping in subarachnoid spaces and cisternal spaces causes late-onset reduction in absorption of CSF.

Illustrative scans of some of our study cases have been shown in - Fig. 19-22.

\section{Conclusion}

$>$ Rate of postoperative hydrocephalus was $15.63 \%$.

$>$ Decompressive craniectomy for traumatic brain injury (and stroke) was the most common condition associated with postop hydrocephalus, f/b surgery for aneurysms, intraventricular and CPA tumors.

$>$ Cases of decompressive craniectomy presented late, more than 30 days, only few cases required diversion procedures during immediate postop period, mostly aneurysm cases and tumors with tumor bed bleed.

$>$ Out of total 6 mortalities, none of them were directly attributable to hydrocephalus, but 2 patients had meningitis leading to death.
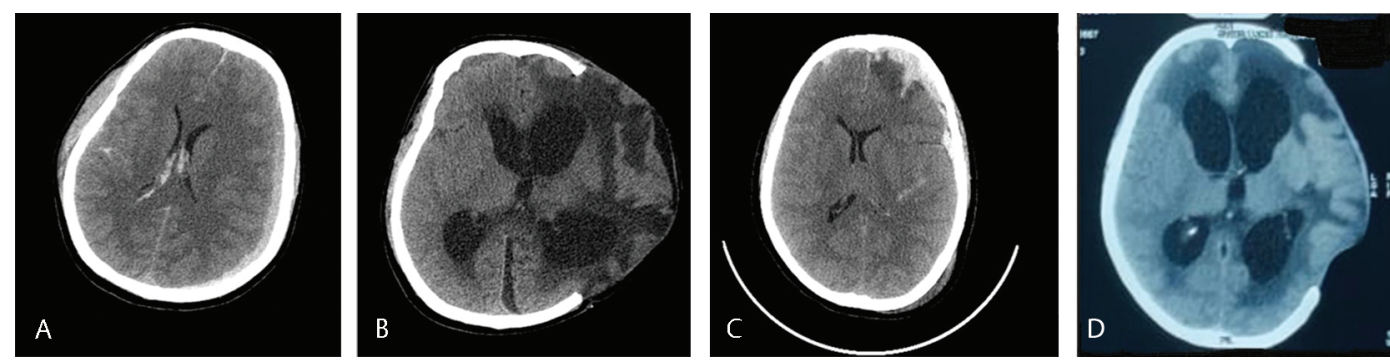

Fig. 19 (A and C) Preop computed tomography (CT) scans of traumatic brain injury patient with left frontotemporoparietal (FTP) acute subdural hematoma (SDH). (B and $\mathbf{D})$ Postop CT scans of respective patients.
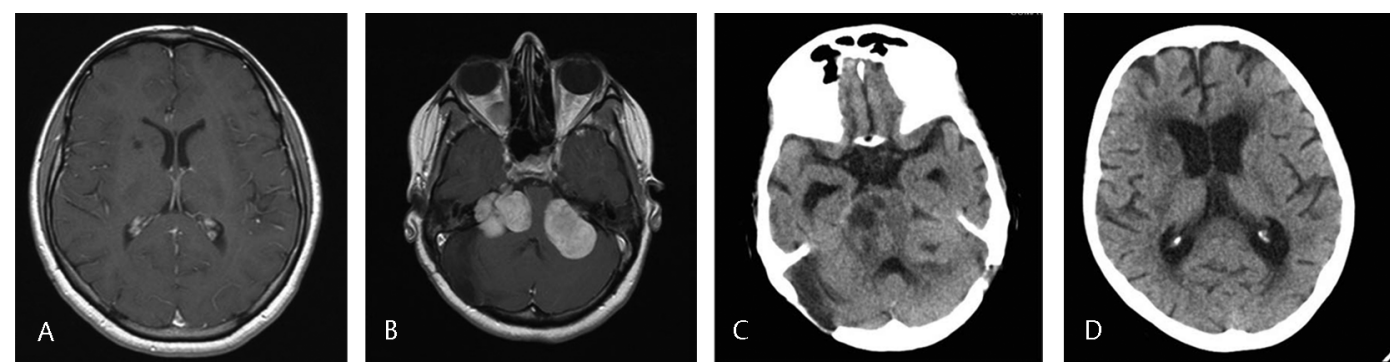

Fig. 20 (A and B) Preop magnetic resonance imaging (MRI) of a patient of B/L vestibular schwannoma. (C and D) Postop computed tomography $(\mathrm{CT})$ scans of the patients after excision of right vestibular schwannoma.
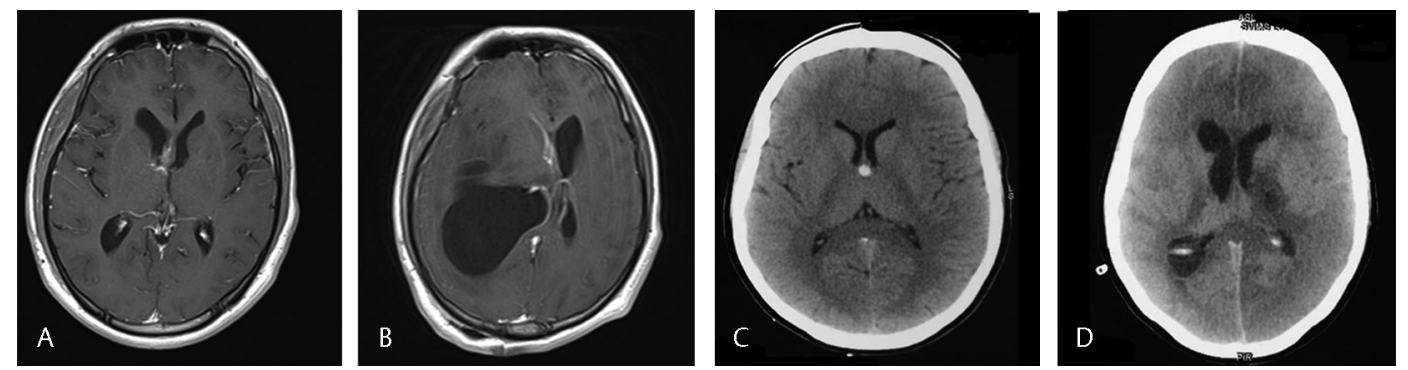

Fig. 21 (A) Preop magnetic resonance imaging (MRI) scan of a case of central neurocytoma, (B) postop MRI scan of the patient, (C) preop computed tomography (CT) scan of a patient with colloid cyst, and (D) postop CT scan of the patient. 

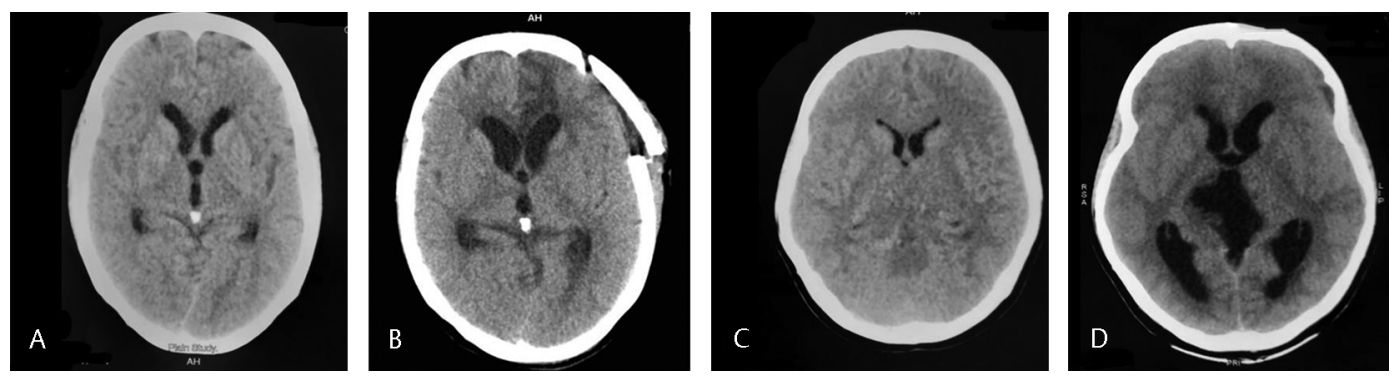

Fig. 22 (A) Preop computed tomography (CT) scan of a case of vertebral artery aneurysm, (B) postop CT scan of the patient, (C) preop CT scan of a patient of pineal region tumor, and (D) postop CT scan of the patient.

$>$ Since most patient presented after initial stabilization, permanent VP shunting was found to be the best option.

$>$ Cases of decompression surgery should be under vigilant follow-up after discharge and even after cranioplasty for risk of development of hydrocephalus and requirement of permanent shunting.

$>$ Cases with IVH or SAH should be considered as future candidate with risk of developing hydrocephalus.

$>$ Lamina terminalis opening whenever possible results in favorable outcome in cases of anterior circulation aneurysms.

$>$ CSF protein analysis in cases of intraventricular and CPA tumors should be done whenever possible, preferably routinely.

\section{Conflict of Interest}

None declared.

\section{References}

1 Ding J, Guo Y, Tian H. The influence of decompressive craniectomy on the development of hydrocephalus: a review. Arq Neuropsiquiatr 2014;72(9):715-720

2 De Bonis P, Pompucci A, Mangiola A, Rigante L, Anile C. Post-traumatic hydrocephalus after decompressive craniectomy: an underestimated risk factor. J Neurotrauma 2010;27(11):1965-1970

3 Hu Q Di G, Shao X, Zhou W, Jiang X. Predictors associated with post-traumatic hydrocephalus in patients with head injury undergoing unilateral decompressive craniectomy. Front Neurol 2018;9:337

4 Sun S, Zhou H, Ding ZZ, Shi H. Risk factors associated with the outcome of post-traumatic hydrocephalus. Scand J Surg 2019;108(3):265-270

5 Nasi D, Gladi M, Di Rienzo A, et al. Risk factors for post-traumatic hydrocephalus following decompressive craniectomy. Acta Neurochir (Wien) 2018;160(9):1691-1698

6 Sinha S, Raheja A, Garg M, et al. Decompressive craniectomy in traumatic brain injury: a single-center, multivariate analysis of 1,236 patients at a tertiary care hospital in India. Neurol India 2015;63(2):175-183

7 Fattahian R, Bagheri SR, Sadeghi M. Development of posttraumatic hydrocephalus requiring ventriculoperitoneal shunt after decompressive craniectomy for traumatic brain injury: a systematic review and meta-analysis of retrospective studies. Med Arh 2018;72(3):214-219

8 Vedantam A, Yamal JM, Hwang H, Robertson CS, Gopinath SP. Factors associated with shunt-dependent hydrocephalus after decompressive craniectomy for traumatic brain injury. J Neurosurg 2018;128(5):1547-1552

9 Chen S, Luo J, Reis C, Manaenko A, Zhang J. Hydrocephalus after subarachnoid hemorrhage: pathophysiology, diagnosis, and treatment. BioMed Res Int 2017;2017:8584753

10 Jartti P, Karttunen A, Isokangas JM, Jartti A, Koskelainen T, Tervonen O. Chronic hydrocephalus after neurosurgical and endovascular treatment of ruptured intracranial aneurysms. Acta Radiol 2008;49(6):680-686

11 Graff-Radford NR, Torner J, Adams HP Jr, Kassell NF. Factors associated with hydrocephalus after subarachnoid hemorrhage. A report of the Cooperative Aneurysm Study. Arch Neurol 1989;46(7):744-752

12 Kwon JH, Sung SK, Song YJ, Choi HJ, Huh JT, Kim HD. Predisposing factors related to shunt-dependent chronic hydrocephalus after aneurysmal subarachnoid hemorrhage. J Korean Neurosurg Soc 2008;43(4):177-181

$13 \mathrm{Nam} \mathrm{KH,} \mathrm{Hamm} \mathrm{IS,} \mathrm{Kang} \mathrm{DH,} \mathrm{Park} \mathrm{J,} \mathrm{Kim} \mathrm{YS.} \mathrm{Risk} \mathrm{of} \mathrm{shunt}$ dependent hydrocephalus after treatment of ruptured intracranial aneurysms: surgical clipping versus endovascular coiling according to Fisher Grading System. J Korean Neurosurg Soc 2010;48(4):313-318

14 Chang SI, Tsai MD, Yen DHT, Hsieh CT. The clinical predictors of shunt-dependent hydrocephalus following aneurysmal subarachnoid hemorrhage. Turk Neurosurg 2018;28(1):36-42

15 Adams H, Ban VS, Leinonen V, et al. Risk of shunting after aneurysmal subarachnoid hemorrhage: a collaborative study and initiation of a consortium. Stroke 2016;47(10):2488-2496

16 Tapaninaho A, Hernesniemi J, Vapalahti $M$, et al. Shunt-dependent hydrocephalus after subarachnoid haemorrhage and aneurysm surgery: timing of surgery is not a risk factor. Acta Neurochir (Wien) 1993;123(3-4):118-124

17 Hao X, Wei D. The risk factors of shunt-dependent hydrocephalus after subarachnoid space hemorrhage of intracranial aneurysms. Medicine (Baltimore) 2019;98(27):e15970

18 Lang SS, Sanborn MR, Ju C, Premjee A, Stein CS, Smith MJ. Hydrocephalus after subarachnoid hemorrhage: a meta-analytic comparison of aneurysm treatments. World J Meta-anal 2014;2(4):171-178

19 Shukla D, Agrawal A. Decompressive craniectomy for acute stroke: the good, the bad, and the ugly of it. Romanian Neurosurg 2014;XXI(3):345-348

20 Waziri A, Fusco D, Mayer SA, McKhann GM II, Connolly ES Jr. Postoperative hydrocephalus in patients undergoing decompressive hemicraniectomy for ischemic or hemorrhagic stroke. Neurosurgery 2007;61(3):489-493, discussion 493-494

21 Agarwalla PK, Stapleton CJ, Ogilvy CS. Craniectomy in acute ischemic stroke. Neurosurgery 2014;74(Suppl 1) :S151-S162

22 Bertullo G. Surgical treatment of malignant cerebral infarction. J Univer Surg. 2017;5(4):20 
23 Beez T, Munoz-Bendix C, Steiger HJ, Beseoglu K. Decompressive craniectomy for acute ischemic stroke. Crit Care 2019;23(1):209

24 Lee JH, Ko Y, Bak KH, Kim YS, Kim JM, Kim CH, et al. Surgical outcome and complications of intraventricular tumors. J Korean Neurosurg Soc 1998;27(6):763-769

25 Lewis AI, Crone KR, Taha J. van Loveren HR, Yeh HS, Tew JM Jr. Surgical resection of third ventricle colloid cysts. Preliminary results comparing transcallosal microsurgery with endoscopy. J Neurosurg 1994;81(2):174-178

26 Kriankumar CK, Deshpande RP, Chandrasekhar YB, Rao IS, Panigrahi M, Babu PP. Clinical management and prognostic outcome of intracranial ventricular tumors: a study of 134 cases. Cancer Res Stat Treat 2019;2:10-15

27 Sabanci PA, Aras Y, Ali A, et al. Transcortical removal of third ventricular colloid cysts: comparison of conventional, guided microsurgical and endoscopic approaches and review of the literature. Turk Neurosurg 2017;27(4):546-557

28 Chen C, Lv L, Hu Y, Yin S, Zhou P, Jiang S. Clinical features, surgical management, and long-term prognosis of intraventricular meningiomas: a large series of 89 patients at a single institution. Medicine (Baltimore) 2019;98(16):e15334

29 Alam S, Uddin NWA, Majumder RM, Hasan MM, Ahmed A. Intraventricular tumor: an analysis of 18 cases. Nepal Journal of Neuroscience 2016;13:23-29

30 Radoi M, Danaila L, Stefanescu F, Petrescu D, Vakilnejad R. Surgery in tumors of the lateral ventricles - last 8 years experience. Romanian Neurosurgery 2014;XXI((1):60-72

31 Fukuda M, Oishi M, Kawaguchi T, et al. Etiopathological factors related to hydrocephalus associated with vestibular schwannoma. Neurosurgery 2007;61(6):1186-1192, discussion 1192-1193

32 Al Hinai Q Zeitouni A, Sirhan D, et al. Communicating hydrocephalus and vestibular schwannomas: etiology, treatment, and long-term follow-up. J Neurol Surg B Skull Base 2013;74(2, B2) :68-74

33 Gerganov VM, Pirayesh A, Nouri M, et al. Hydrocephalus associated with vestibular schwannomas: management options and factors predicting the outcome. J Neurosurg 2011;114(5):1209-1215

34 Khan B, Ikramalam AM, Khanzada K. Surgical complications following removal of cerebello-pontine angle (CP) lesions. Pak J Neurol Surg 2018;22(4):183-186
35 Lee S, Seo SW, Hwang J, et al. Analysis of risk factors to predict communicating hydrocephalus following gamma knife radiosurgery for intracranial schwannoma. Cancer Med 2016;5(12):3615-3621

36 Betka J, Zvěřina E, Balogová Z, et al. Complications of microsurgery of vestibular schwannoma. BioMed Res Int 2014;2014:315952

37 Kazan S, Acikbas C, Demirez I, Tuncer R, Verent SM. The factors required for $\mathrm{V}$-P shunting in children with posterior fossa tumors. Turk Neurosurg 1998;8:71-75

38 Aljubour RM, Alomari AK, Musharbash AF. Risk factors for Ventriculoperitoneal shunting in children with posterior fossa tumor.Journal OfThe Royal Medical Services 2017;24(1):45-49

39 Molla ES, Hamza E. Management of secondary hydrocephalus associated with posterior fossa lesions in children (different modalities of treatment) Egyptian J Neurosurg 2016;31(3):157-166

40 Hamdan RA, Essa AE. Posterior fossa intra-axial tumors: surgical outcomes. Med J Cairo Univ 2018;86(7):3433-3439

41 Bateman GA, Fiorentino M. Childhood hydrocephalus secondary to posterior fossa tumor is both an intra- and extraaxial process. J Neurosurg Pediatr 2016;18(1):21-28

42 Agam M, Wedemeyer AM, Carmichael DJ, Weiss HM, Zada G. Complications associated with transsphenoidal pituitary surgery: experience of 1171 consecutive cases treated at a single tertiary care pituitary center. Clin Neurosurg 2017;64(1):237

43 Chowdhury T, Prabhakar H, Bithal PK, Schaller B, Dash $\mathrm{HH}$. Immediate postoperative complications in transsphenoidal pituitary surgery: a prospective study. Saudi J Anaesth 2014;8(3):335-341

44 Janduga CC, Esguerrab MJ, Panilagaoa G, Mejiaa A, Ramab J, Bilocurad EF. In-hospital postoperative complications in patients with pituitary adenoma who underwent pituitary surgery from January 2010 to December 2015: a multicenter study. J Endocrinol Metab 2017;7(4):122-130

45 Alzhrani G, Sivakumar W, Park MS, Taussky P, Couldwell WT. Delayed complications after transsphenoidal surgery for pituitary adenomas. World Neurosurg 2018;109:233-241

46 Agam MS, Wedemeyer MA, Wrobel B, Weiss MH, Carmichael JD, Zada G. Complications associated with microscopic and endoscopic transsphenoidal pituitary surgery: experience of 1153 consecutive cases treated at a single tertiary care pituitary center. J Neurosurg 2018;130:1-8 